\title{
Efficacy of Cyanoacrylate Glue Ablation of Primary Truncal Varicose Veins Compared to Existing Endovenous Techniques: A Systematic Review of the Literature
}

\author{
Anthony Pio Dimech, MD, MRCSEd, MSc ${ }^{10}$ \\ Kevin Cassar, MD (Malta), MMEd (Dundee), FRCS (Ed), MD (Aberdeen), FRCS (Intercoll)2 \\ 1 Vascular Unit, Department of Surgery, Mater Dei Hospital, Msida, \\ Malta \\ 2 Vascular Unit, Department of Surgery, Mater Dei Hospital, Msida, Malta \\ Address for correspondence Anthony Pio Dimech, MD, MRCSEd, MSc, \\ 26, National Assembly Street, San Gwann, SGN 3031, Malta \\ (e-mail: anthony.dimech@gmail.com).
}

Surg J 2020;6:e77-e86.

\begin{abstract}
Keywords

- n-butyl 2 cyanoacrylate

- radiofrequency

- laser

- saphenous vein

- varicose veins

Introduction One-third of adults in the United States and United Kingdom suffer from varicose veins. $n$-butyl-2-cyanoacrylate (NBCA) glue is a novel endovascular, nontumescent, nonthermal ablation technique for treatment of this condition. It has proved effective in multiple studies since its first use in 2013. The aim of this systematic review is to assess the efficacy of NBCA in ablating primary truncal varicose veins and eliminating reflux compared with existing endovascular techniques. Secondary outcomes include complications and quality of life.

Methods PRISMA was used as a guide and studies were screened for risk of bias and methodological quality. Subjects had to be $\geq 18$ years of age and followed-up posttreatment with color Duplex ultrasound (DUS). Eligibility criteria included saphenofemoral junction (SFJ) or saphenopopliteal junction (SPJ) incompetence with reflux down truncal veins lasting $>0.5$ seconds on DUS interrogation and a Clinical, Etiological, Anatomical, and Pathophysiological classification of venous disorders ranging between $\mathrm{C} 1$ and $\mathrm{C} 6$.

Results Out of 2,910 patients (3,220 veins) in 17 studies, 1,981 were administered NBCA, 445 radiofrequency ablation (RFA), and 484 endovenous laser ablation (EVLA) with mean procedure times of $25.7,23.2$, and 28.7 minutes, respectively. Mean recruitment period was 9 months (1-36 months) and followed-up for an average of 12.3 months (1-36 months). The majority were C2 to C3. Two-year occlusion rates were 93.7, 90.9, and 91.5\% for NBCA, RFA, and EVLA, respectively. NBCA-treated patients experienced the least complications, with bruising, phlebitis, and pain being the most prevalent. Quality of life improved equally in all three modalities.

Conclusion NBCA is simple to administer, safe, and effective even without compression stockings. Further studies are required to assess longer-term benefit and the effect of anticoagulation on vein obliteration.
\end{abstract}

Thirty-five percent of adults in the United States and United Kingdom have chronic lower limb superficial venous disease. ${ }^{1}$ Varicose veins are more common in females, with a predilection toward the older age group and may run in families. A body mass index $>30 \mathrm{~kg} / \mathrm{m}^{2}$ is a risk factor for

received

December 2, 2019 accepted after revision February 11, 2020
DOI https://doi.org/ 10.1055/s-0040-1708866. ISSN 2378-5128. chronic venous insufficiency. ${ }^{2}$ Symptoms include limb heaviness, ache, and edema. Skin changes such as spider veins, varicose veins, hemosiderin deposition, inflammation, lipodermatosclerosis, and ulceration often follow in untreated cases. $^{2-4}$
Copyright $\odot 2020$ by Thieme Medical Publishers, Inc., 333 Seventh Avenue, New York, NY 10001, USA. Tel: +1(212) 760-0888.
License terms

(c) (9) 
The 2013 National Institute for Health and Care Excellence (NICE) guideline on diagnosis and management of varicose veins (updated March 2018) recommends radiofrequency ablation (RFA) or endovenous laser ablation (EVLA) as first line treatment for truncal reflux. Second-line is ultrasoundguided foam sclerotherapy. Open surgery is indicated only if the other methods are unsuitable. Any incompetent tributaries are preferentially treated in the same session. Compression hosiery should not be used longer than 7 days after intervention, and is first choice only in pregnancy or if the previously mentioned interventions are unsuitable. ${ }^{5}$ NICE also issued a specific guideline in 2015 on the use of $n$-butyl-2-cyanoacrylate (NBCA) for varicose veins but did not promote its routine use. $^{6}$ Almeida et al reported the first human application of NBCA for incompetent great saphenous veins (GSVs) in 2013. All 38 veins under study were obliterated at 48 hours and $92 \%$ at 1 year with minor short-lasting adverse effects. ${ }^{7}$

The aim of this systematic review is to assess the efficacy of NBCA in ablating primary truncal varicose veins and eliminating reflux compared with existing endovascular techniques in the immediate, medium, and long-term settings. Secondary outcomes include complications, patient acceptability, and quality of life.

\section{Methods}

\section{Protocol and Search Strategy}

This review is registered in PROSPERO database (registration code: CRD42018106323) and followed the PRISMA checklist. ${ }^{8,9}$ One author performed a literature search and data extraction up to October 2018 with no set date range and using established MeSH vocabulary in PubMed, EMBASE, Scopus, Cochrane Library, and ScienceDirect. Search terms were: "varicose vein," "saphenous vein," "glue," " $n$-butyl cyanoacrylate," and " $n$-butyl 2 cyanoacrylate." References and article suggestions by search engines were assessed to identify more relevant studies. Duplicates were removed and further exclusions performed after reviewing abstracts. The chosen manuscripts were then scrutinized while applying inclusion and exclusion criteria.

\section{Inclusion and Exclusion Criteria}

Human randomized controlled trials (RCTs), cohort studies, and case reports in English language involving the use of NBCA to treat primary truncal varicose veins (i.e., GSV, small saphenous vein [SSV], and anterior accessory saphenous vein [AASV]) were included. If more than one modality was used, the said manuscript was only included if the data for NBCA could be fully extracted. Studies excluding NBCA glue or comparing NBCA with treatments other than RFA, EVLA, or foam sclerotherapy were excluded. ${ }^{1,2,10,11}$-Supplementary Table 1 (online only) summarizes patient characteristics for inclusion/exclusion.

\section{Primary and Secondary Outcomes}

Primary outcome was successful obliteration of lumen of target vein, defined as occlusion of the entire treated vein segment with no discrete segments of patency exceeding $5 \mathrm{~cm}$, confirmed on color Duplex ultrasound (DUS) after the procedure. ${ }^{1}$ Follow-up DUS assessments at 3 days, 7 days, 1 month, 3 months, 6 months, 1 year, and 2 years were examined.

Influence of vein length, diameter, NBCA device, and postoperative compression stockings on early (3 months) and intermediate term ( 6 months, 1 year) occlusion rate was taken as secondary outcomes. Vein length was taken as a mean value incorporating GSVs, SSVs, and AASVs with no distinction between the three. Where a particular vein diameter was taken at different levels, the mean of these values was calculated.

Clinical, Etiological, Anatomical, and Pathophysiological classification and Varicose Clinical Severity Score (VCSS) were used to measure severity of varicose veins at baseline and postintervention. Quality of life was primarily investigated using the Aberdeen Varicose Vein Questionnaire (AVVQ). ${ }^{2}$ "Thrombophlebitis" and "abnormal skin reactions" in treatment zones were included with the general term "phlebitis." ${ }^{12,13}$ All thrombus extensions into the deep venous systems were classified as deep vein thromboses (DVTs). Complications common to the three ablation modalities were evaluated.

\section{Data Extraction}

Any uncertainties in the literature were discussed with the second author and the authors of the original manuscripts where applicable. Risk of methodological bias was explored using the Cochrane Risk of Bias tool for RCTs. ${ }^{14,15}$ Quality assessment was performed using the Downs and Black quality assessment tool (for RCTs) and the National Heart, Lung and Blood Institute: Quality Assessment Tool for Before-After (Pre-Post) Studies With No Control Group (NHLBI-QAT). ${ }^{16,17}$

\section{Statistical Analysis}

Continuous variables were represented by means, standard deviations, and ranges. Categorical variables were shown in actual numbers and percentages. Scatter plots were created using Python version 3.7 (Python Software Foundation, Beaverton, DE). Statistical analysis was done using IBM SPSS Statistics software (IBM Corp. Released 2013. IBM SPSS Statistics for Windows, Version 22.0. Armonk, NY). Spearman's correlation and Mann-Whitney U-test were performed on groups of subjects at 3, 6, and 12-month intervals following NBCA treatment. These tests were chosen because continuous variables were not normally distributed. Level of statistical significance was taken as $p<0.05$.

\section{Results}

\section{Description of Studies}

The PRISMA flowchart (-Fig. 1) depicts the choice of manuscripts at different phases. One case report was identified but not reviewed as it contained heterogeneous data. ${ }^{18}$ All were published in peer-reviewed indexed scientific journals. There were 3038 participants (3,220 veins). A subgroup of 128 patients were excluded because of the missing data. ${ }^{19-21}$ of the 2910 patients who were included, 1981 received NBCA, 445 RFA, and 484 EVLA. Comparison of NBCA with RFA and/or EVLA was performed in three RCTs and two retrospective studies. $^{10,12,19,21,22}$ No studies compared NBCA with sclerotherapy, 


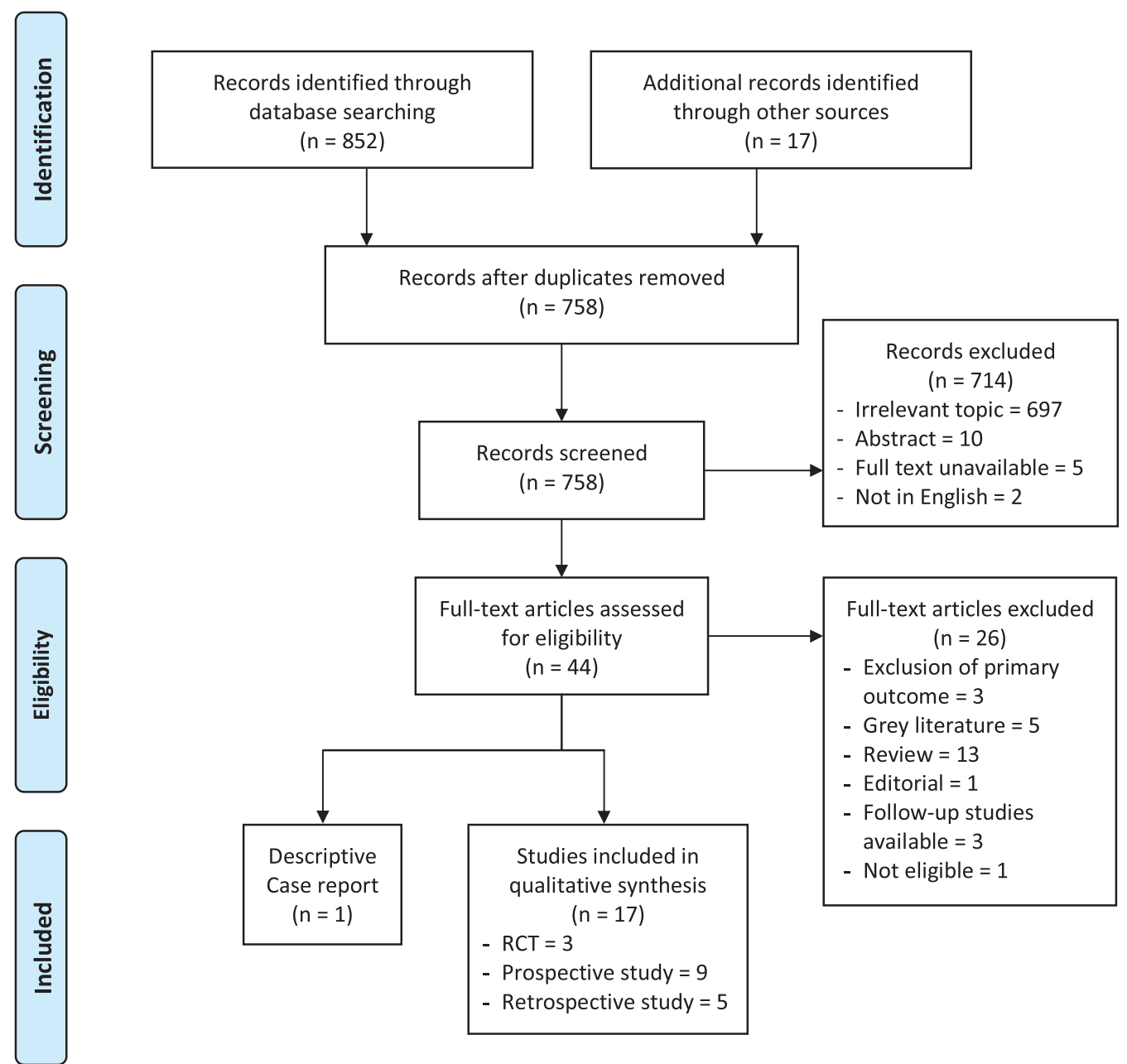

Fig. 1 PRISMA flowchart depicting the process of selection of articles. RCT, randomized controlled trial.

but this was frequently used an adjunctive treatment. Levels of evidence for therapeutic studies were judged using criteria from the Centre for Evidence-Based Medicine. ${ }^{23}$

\section{Quality and Risk of Bias Assessment}

\section{Randomized Controlled Trials}

Risk of bias for RCTs is illustrated in - Table 1. Bozkurt and Yilmaz pseudorandomized their patients to alternate EVLA and NBCA. This led to a high risk of selection bias. ${ }^{10}$ Randomization was better in the VeClose trial and the study by Eroglu and Yasim. 1,12,19 The former also included "roll-in cases" so that investigators could achieve familiarity with the NBCA procedure. DUS assessments were not always performed by blinded personnel. Attrition bias was unclear in two RCTs as drop-outs were not formally analyzed. ${ }^{13,20}$ Effect of adjunctive therapies and postoperative compression stockings was not evaluated. Only one performed power analysis. ${ }^{19}$ Primary and secondary end points were clearly reported in all RCTs.

\section{Prospective and Retrospective Studies}

Prospective studies were of a higher methodological quality (-Supplementary Fig. 1 and - Supplementary Table 2 [online only]). Selection bias toward bilateral varicose veins was observed in one prospective and one retrospective study. ${ }^{25,26}$ Another reported a modification of intervention after commencement of data collection which improved the complication rate in the remaining patients. ${ }^{27}$ Blinding of assessors was not possible. The loss to follow-up for NBCA was $23.7 \%$ in one manuscript. ${ }^{28}$ Another started with 34 patients and had $26 \%$ loss at 1 month. ${ }^{13}$ One prospective and one retrospective study reported percentage occlusion rate only once at 1 month and 1 year respectively despite mentioning several follow-up intervals in the methodology. ${ }^{13,22}$ Coincidentally, the former did not have sufficient patients at the target 3-month interval to formulate strong conclusions. ${ }^{13}$ Another study did not differentiate between the short- ( 1 week) and mid-term ( 2 months) outcome results, which instead were displayed as combined absolute values. $^{21}$

\section{Population and Operative Details}

Study characteristics are summarized in -Tables $\mathbf{2}$ and $\mathbf{3}$.

\section{n-Butyl-2-Cyanoacrylate}

Mean age of the recruited population was 49.3 years and $64.8 \%$ were females. Most procedures from Turkey used the VariClose NBCA system (Biolas, FG Group, Ankara, Turkey). ${ }^{10,19,20,22,29-31}$ One study used VenaBlock adhesive 
Table 1 Traffic light plot illustrating risk of bias of the included RCTs (using the Cochrane risk of bias tool) and Downs and Black quality assessment scores

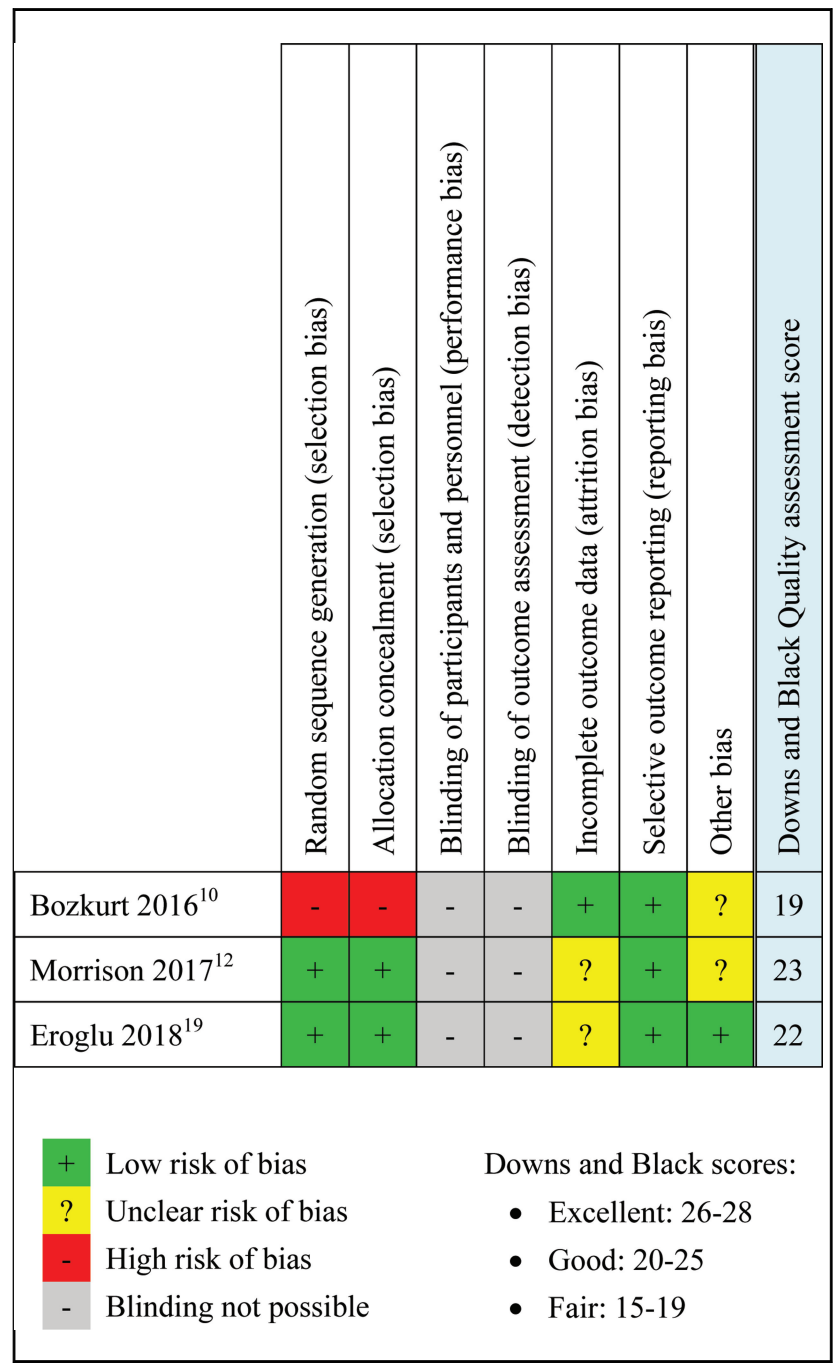

Abbreviation: $\mathrm{RCT}$, randomized controlled trials.

Note: The score for item 27 in the Downs and Black checklist was modified to determine whether power analysis was conducted (yes $=1$ point) or not (no $=0$ points). So, the maximum score for the checklist was 28 instead of $32 .{ }^{24}$

(Invamed, Ankara, Turkey). ${ }^{27}$ The rest utilized the VenaSeal system (Medtronic, Dublin, Ireland). ${ }^{12,13,21,25,26,28,32-34}$ All procedures commenced by cannulation of the target vein with an introducer needle under ultrasound guidance at the most distal point of reflux. The position of the delivery catheter tip distal to SFJ or SPJ ranged from 3 to $5 \mathrm{~cm}$. The average volume of NBCA glue used was $1.3 \mathrm{~mL}$ (range $0.87-2 \mathrm{~mL}$ ) to treat veins with a mean length of $30.8 \mathrm{~cm}$ (range $24-43 \mathrm{~cm}$ ) and diameter of $7 \mathrm{~mm}$ (range $5.6-8 \mathrm{~mm}$ ). Procedure technique varied depending on the choice of NBCA device.

For VenaSeal, two initial $0.09-\mathrm{mL}$ glue aliquots were injected $1 \mathrm{~cm}$ apart, followed by $3 \mathrm{~cm}$ pullbacks between each trigger pull. Pressure with Ultrasound (US) probe was applied to occlude the SFJ/SPJ before dispensing the first two aliquots to prevent glue from entering the deep venous system.
The first two injections were followed by 3 minutes of compression. US probe pressure was applied for 30 seconds after subsequent injections.

The VariClose system used a similar technique in terms of initial pressure to occlude the SFJ or SPJ before first injection. The trigger was pressed for 5 seconds while withdrawing the catheter by $10 \mathrm{~cm}$ (giving $0.06 \mathrm{~mL}$ of glue at $2 \mathrm{~cm} / \mathrm{s}$ ). Pressure over each $10-\mathrm{cm}$ segment of treated vein was applied for 30 seconds. Once the entire vein was treated, a further 30 seconds of pressure over the entire target vein was applied. VenaBlock used a similar method.

Recording of duration of NBCA procedures was not standardized. Two prospective studies calculated duration from the time of insertion of NBCA delivery catheter to the time of withdrawal (mean 19.3 minutes). ${ }^{28,33}$ The period from establishing venous access to applying the final bandages was taken as procedure time in another two prospective studies, with an average of 38.7 minutes. ${ }^{13,32}$ An even broader timing interval extended from skin preparation to final bandaging, including phlebectomies (mean 64 minutes). ${ }^{25,26}$ One operator performed the procedures under intravenous sedation, which further extended length of intervention. ${ }^{13}$

\section{Radiofrequency Ablation}

Three studies compared NBCA with RFA. ${ }^{12,19,21}$ The mean age of patients was 51 years and $72.8 \%$ were females. The devices used were ClosureFast (VNUS Medical Technologies, San Jose, CA) and Venefit (Medtronic of Canada Ltd, Vancouver, British Columbia, Canada). Both are similar and require perivenous tumescent anesthesia. Procedure duration was recorded in two RCTs and results were conflicting. ${ }^{12,19}$ On one side, NBCA took longer than RFA ( 24 vs. 19 minutes, $p<0.01$ ). ${ }^{1}$ The other RCT identified a significant reduction in favor of NBCA (15.3 vs. 27.3 minutes, $p<0.001) .{ }^{19}$ Neither documented the actual commencement and completion of recording.

\section{Endovenous Laser Ablation}

EVLA was performed on 246 females (50.8\%). Mean age was 44.4 years. Evlas Circular fiber EVLA kit (Biolas, Ankara, Turkey) was used in all three studies. It operates at a wavelength of $1,470 \mathrm{~nm}$ and uses tumescent anesthesia. Peak temperature reaches $1200^{\circ} \mathrm{C}$ (compared with $120^{\circ} \mathrm{C}$ for RFA). One retrospective analysis mentioned the application of manual pressure over the treated vein during laser fiber withdrawal but its benefit in terms of promoting vein closure was not investigated. $^{22}$ Compression stockings were prescribed following all EVLA procedures and all agreed that EVLA took significantly longer than NBCA or RFA $(p<0.001) .^{10,19,22}$

\section{Postoperative Success}

\section{Occlusion Rate}

-Fig. 2 shows a substantial initial success rate after NBCA ablation followed by RFA and EVLA, respectively. Although limited, the 2-year NBCA data are superior. There is negligible difference between RFA and EVLA plots from 6 months onward. Partial and complete recanalization rates were lowest for NBCA throughout the period of follow-up. 


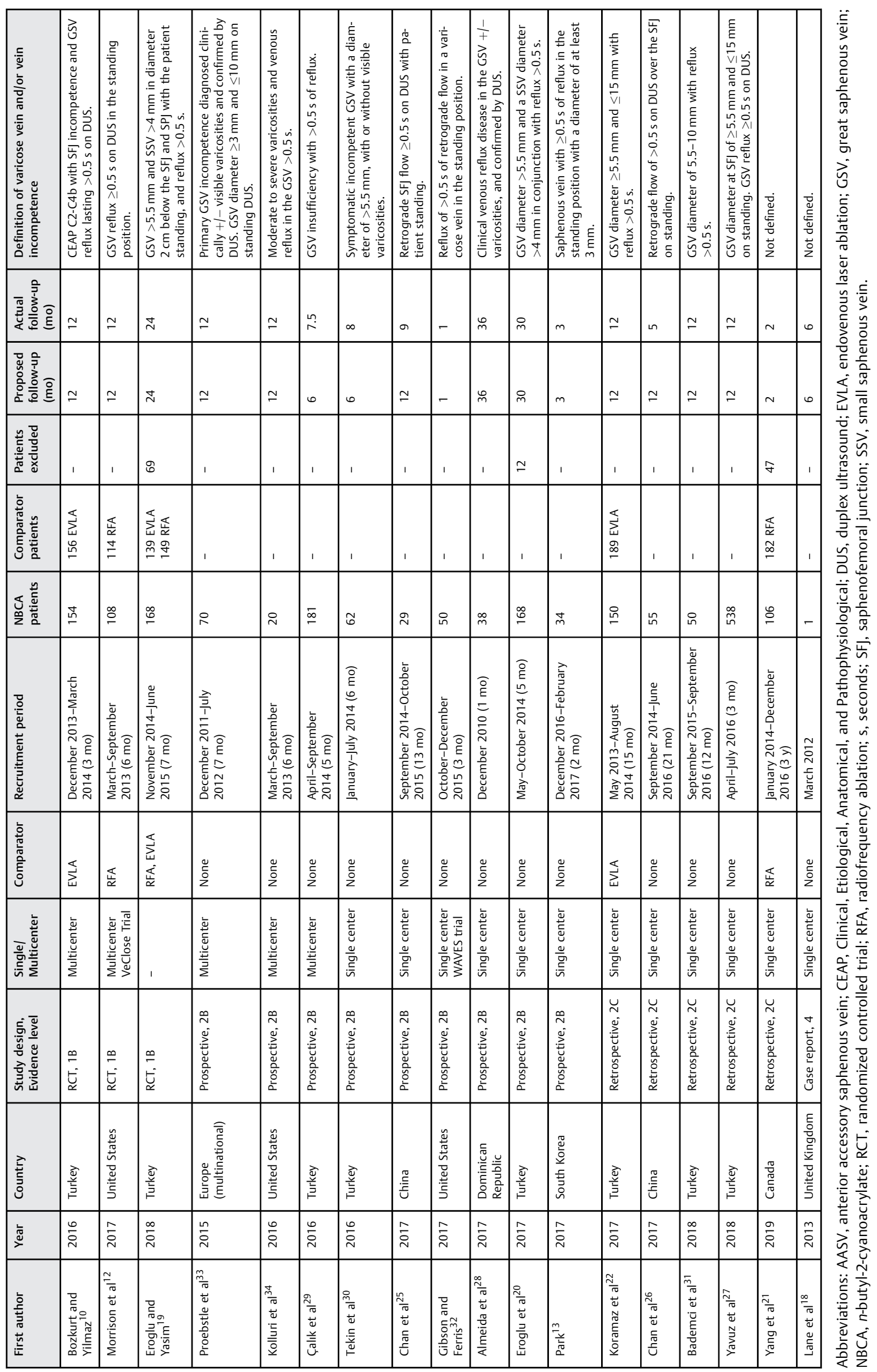




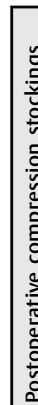
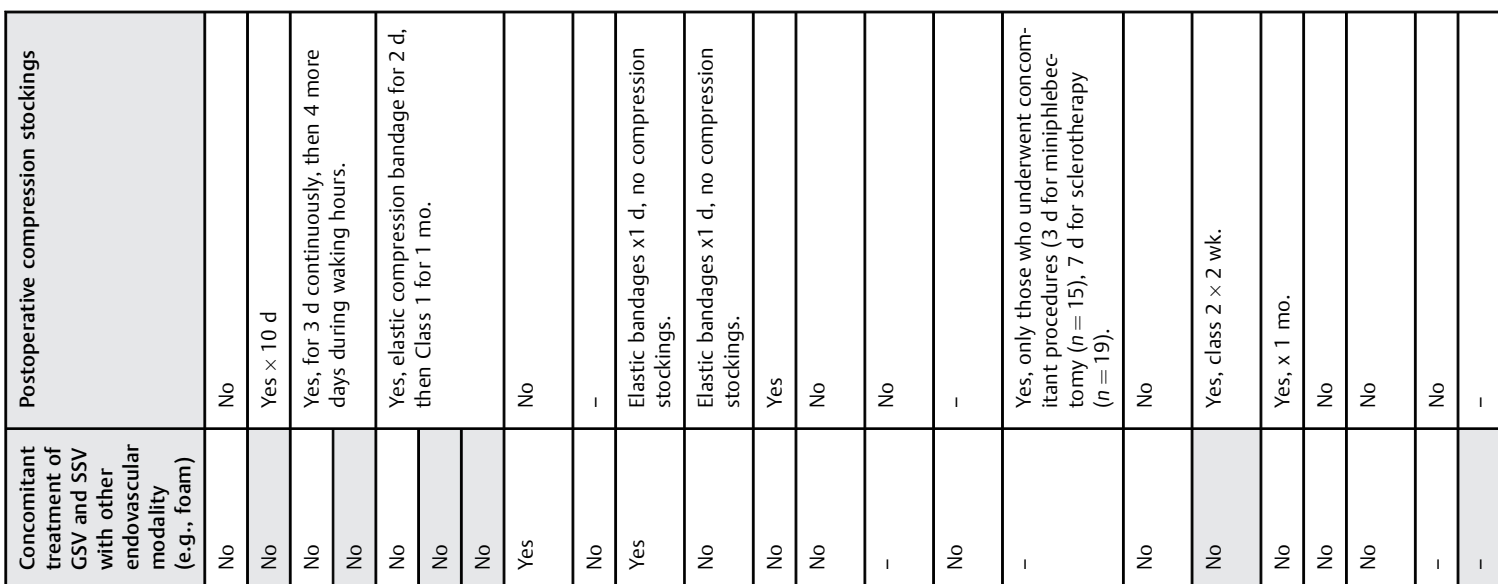

,

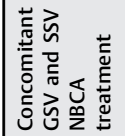

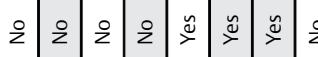

$\stackrel{2}{2}$

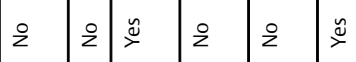

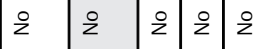

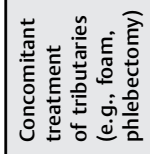

z

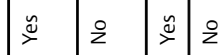

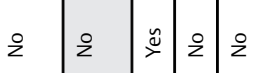

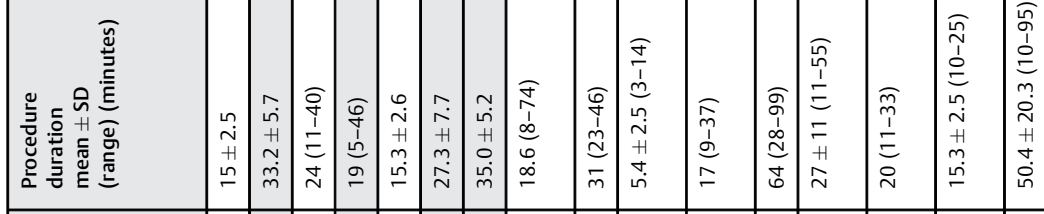

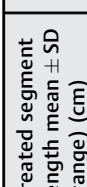

政

\begin{tabular}{ll|l|l|l|l} 
& & & & \\
\hline
\end{tabular}

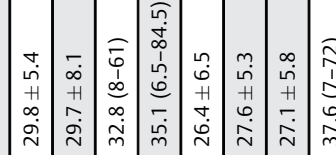

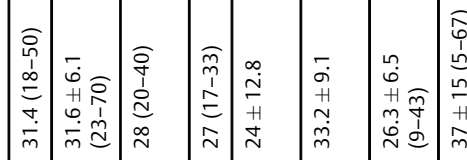

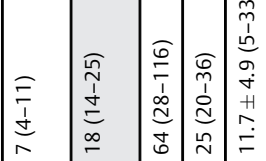

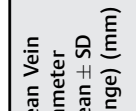

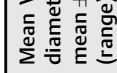

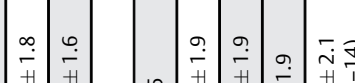

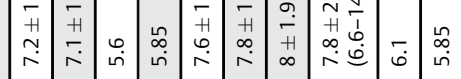

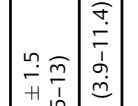

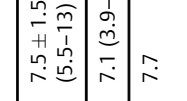

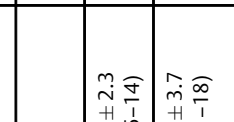

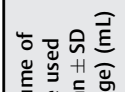

है

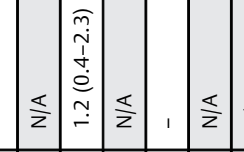

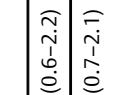

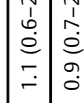

$\ln$

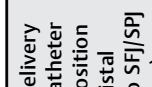

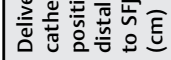

宾㟥

ڤે

ॐે

\begin{tabular}{ll|l|l|l|l} 
& & & & & \\
\hline
\end{tabular}

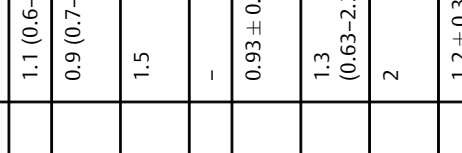

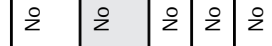




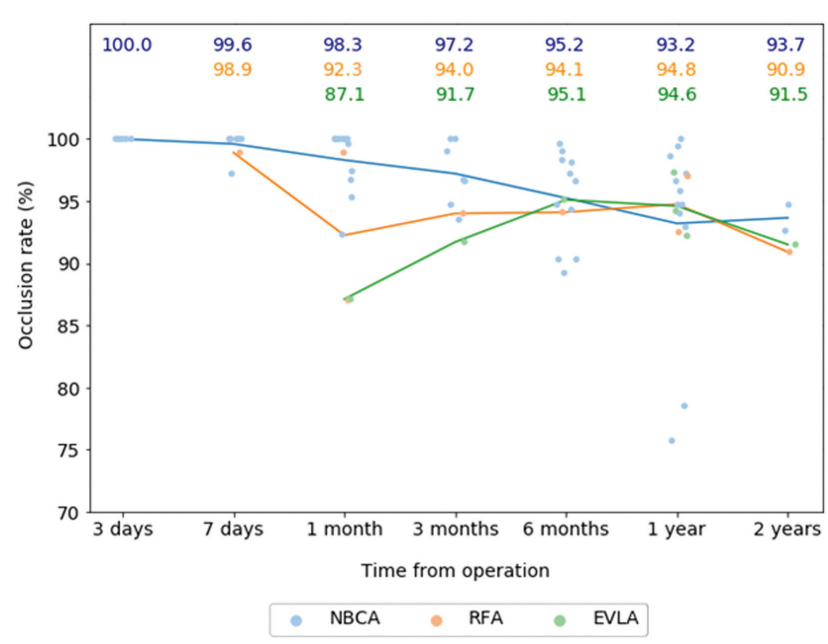

Fig. 2 Categorical scatter point plot with the line of best fit representing the mean occlusion rates at each time interval. Color-coded numbers above the plots denote mean percentage occlusion rate.

\section{Complications}

There were no pulmonary embolic events. Nine cases of postablation DVT were observed in the NBCA group (-Fig. 3). ${ }^{21,25,26,29,32,33}$ Four DVTs were reported in the RFA group and three following EVLA (endovenous heat-induced thrombi Class 1) without statistical significance. ${ }^{12,19,21,22}$ All resolved with or without heparin treatment. Bruising was least in NBCA-treated patients. ${ }^{1,25,26}$ All RCTs reported a statistically significant lower incidence of ecchymosis in the NBCA group. ${ }^{1,10,19}$ One explanation is that repeated injections are required for tumescent anesthesia in thermal ablation methods while these are avoided in NBCA. ${ }^{1}$ However, one retrospective comparative analysis found that five (2.65\%) of EVLA-treated patients developed bruising which did not reach the level of significance compared with NBCA, even though such adverse

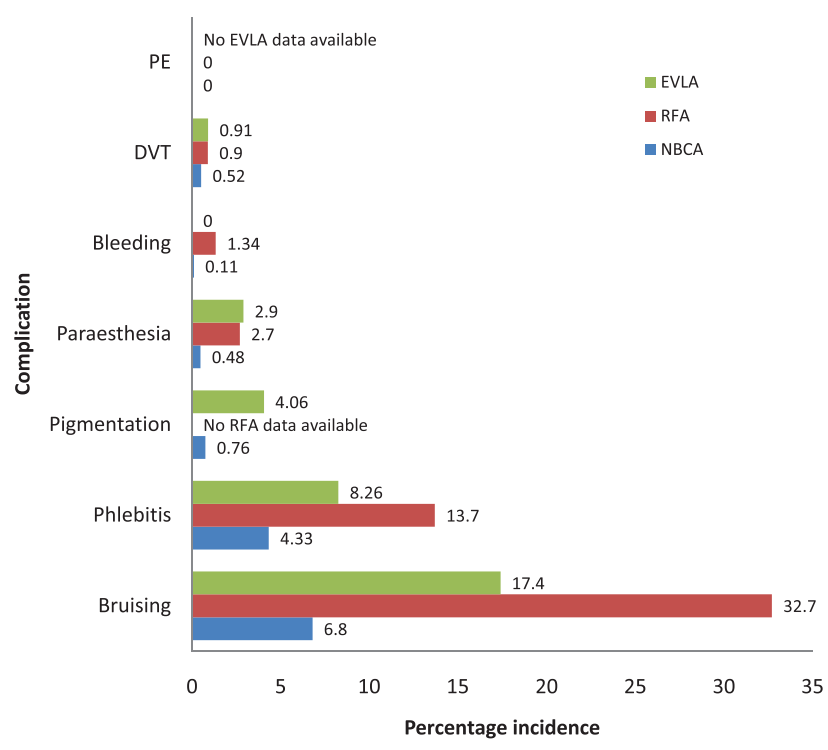

Fig. 3 Bar chart displaying proportion of patients (\%) experiencing a complication for each treatment modality. EVLA, endovenous laser ablation; NBCA, n-butyl cyanoacrylate; RFA, radiofrequency ablation. event was absent in the latter cohort. ${ }^{22}$ One prospective and one retrospective study by the same author using NBCA concluded that bruising resulted from stab avulsion sites which was performed in the same sitting. ${ }^{25,26}$ Three studies documented minor point bruising at the access site of NBCA delivery catheter due to residual NBCA being applied close to the entry point. ${ }^{27,31,33}$ Bleeding and hematoma formation were reported in one patient who underwent NBCA ablation and two post-RFA, the latter being at the site of vein access. ${ }^{19,30}$ Paresthesia was temporary and less frequent in the NBCA group. $^{10,12,21,22,25}$ Seven patients complained of pigmentation at the treatment site after NBCA ablation which improved significantly over 1 year. ${ }^{10,13,31}$ A higher number was reported after EVLA and were shown to be statistically significant. ${ }^{22}$ All were temporary. Phlebitis after NBCA ablation was significantly less than post-RFA or EVLA. ${ }^{21,22}$ One RCT reported the opposite, but failed to reach significance level. ${ }^{1}$ Most reactions were transient and self-limiting or resolved with a short course of nonsteroidal anti-inflammatory drugs. ${ }^{1,13,26,32,33}$ Antibiotics were prescribed in two studies. $^{22,29}$-Supplementary Fig. 2 compares the different NBCA glue products with the proportion of veins having postoperative phlebitis. Although inconsistently and heterogeneously recorded, intraoperative pain experience was least for cyanoacrylate procedures, presumably because of the lack of tumescent anesthesia and heat generation. It was therefore better tolerated. ${ }^{10,19,32}$ Most subjects returned to work the following day and this was superior to RFA and EVLA. ${ }^{19,20,25,26,32}$ One patient developed generalized urticaria after the first week of treatment indicating delayed NBCA allergy. This settled with oral antihistamines and steroids. ${ }^{32}$

\section{vCSS and Quality of Life Scores}

All endovenous ablation modalities exhibited a statistically significant decline in VCSS scores over time. $^{10,12,19,20,22,25-29,31,33,34}$ Two RCTs reported no difference between NBCA and EVLA during follow-up and another favored NBCA at 2 years $(p<0.001) .^{10,19,22}$ Two prospective analyses by Gibson and Park were analyzed separately because they used the revised version of VCSS. ${ }^{35}$ Mean baseline scores were $6.5 \pm 2.4$ (3-14) and $4.3 \pm 2.1$ (2-13). At 30 days, these improved respectively to $1.8 \pm 1.4(0-6)$ and $1.2 \pm 1.0(0-5)(p<0.001$ and 0.024$) .{ }^{13,32}$

The AVVQ was the main reporting modality for quality of life. Its downward decline from baseline was significant, consistent, and similar in all groups. Few manuscripts utilized other quality of life scores including EQ-5D, EQ-5D TTO, CIVIQ and SF-36. All except SF-36 exhibited a significant improvement from baseline. 1,12,25,26,29,32-34

\section{Influence of Variables on Occlusion Rate}

Occlusion rate after cyanoacrylate glue treatment is not influenced by vein length, diameter, dispensing device, or use of postoperative compression stockings ( - Table 4).

\section{Discussion}

Monomeric cyanoacrylate compounds polymerize upon contact with anionic components of plasma, a process 
Table 4 Analysis of the effect of four variables on occlusion rate of NBCA-treated veins (Spearman's correlation, MannWhitney $U$ test $^{\mathrm{b}}$ )

\begin{tabular}{|l|l|l|l|l|}
\hline \multicolumn{4}{|l|}{$p$-Values } \\
\hline $\begin{array}{l}\text { Occlusion } \\
\text { rate } \\
\text { interval }\end{array}$ & $\begin{array}{l}\text { Vein } \\
\text { length }^{\mathrm{a}}\end{array}$ & $\begin{array}{l}\text { Vein } \\
\text { diameter }^{\mathrm{a}}\end{array}$ & $\begin{array}{l}\text { NBCA } \\
\text { device }^{\mathrm{b}}\end{array}$ & $\begin{array}{l}\text { Compression } \\
\text { stockings }^{\mathrm{b}}\end{array}$ \\
\hline $3 \mathrm{mo}$ & 0.728 & 0.538 & 0.593 & 0.564 \\
\hline $6 \mathrm{mo}$ & 0.423 & 0.413 & 0.295 & 0.521 \\
\hline $12 \mathrm{mo}$ & 0.931 & 0.160 & 0.873 & 0.240 \\
\hline
\end{tabular}

Abbreviation: NBCA, N-butyl-2-cyanoacrylate.

consisting of three distinct phases: initial rapid polymerization with linear increase in tensile forces lasting approximately 10 seconds (phase 1 ), stable tensile forces lasting approximately 60 seconds (phase 2 ) followed by a more rapid rise of tensile forces (phase 3 ). ${ }^{36}$ The process of luminal fibrosis after glue injection takes several weeks before it becomes permanent. ${ }^{37}$ Adjunctive treatments (phlebectomy or foam sclerotherapy) risk a type 2 error and the confounding potential of these treatments is a subject of future trials. ${ }^{10,12,13,19,20,25-27,29,33}$

There were outliers that skewed the NBCA occlusion data at 6 months and 1 year, leading to a dip in success rate at these intervals. ${ }^{25,26,30}$ Bissacco et al reviewed 1,000 NBCA cases in seven studies (two prospective, four retrospective) and found $96.8 \%$ of veins occluded at 12 months. ${ }^{38}$ Two studies reported NBCA occlusion beyond the 2-year interval, and these were $94.1 \%$ at 30 months and $94.7 \%$ at 36 months, respectively. ${ }^{20,28}$ Time to complete occlusion was shorter for NBCA than any of the endothermal modalities because veins are instantly occluded by approximation of their intima, while thermal ablation is dependent on vein wall destruction and subsequent fibrosis-a biological process which takes longer. ${ }^{12}$ The outcomes of RFA versus EVLA have been extensively studied in previous trials. Using the ClosureFast RFA system on 200 limbs (163 GSVs and 41 SSVs), Choi et al reported 94.6\% occlusion in GSV and $94.5 \%$ in SSV at 13.9 months, which is similar to our data. ${ }^{39}$ A prospective double-blind RCT comparing RFA versus EVLA (159 patients-79 RFA, 80 EVLA) by Nordon et al identified a $100 \%$ occlusion at 7 days. The 3 -month occlusion rate reached $97 \%$ for RFA and $96 \%$ for EVLA. There was no significant difference between the groups. ${ }^{40}$ In the LARA study, Goode et al reported 95 and 74\% occlusion rate for RFA at 10 days and 9 months respectively. For EVLA, these were 95 and 78\%. The high failures at 9 months were attributed to incorrect setting on the RFA which improved to $98 \%$ upon adjustment. No reasons for EVLA failures were given but the short wavelength of the laser used $(810 \mathrm{~nm})$ and pullback speed might be implicated. ${ }^{41}$

Recanalization does not necessarily signify return of symptoms as many maintain a good quality of life and anticoagulation does not appear to be a predisposing factor. ${ }^{12,25,27,29}$ NBCA is noninferior to RFA in terms of freedom from recanalization. ${ }^{12}$ Chan et al found a significant risk in their earlier study with vein diameters $\geq 8 \mathrm{~mm}$, which was reduced to $\geq 6.6 \mathrm{~mm}$ in a subsequent analysis. ${ }^{25,26}$ This was contradicted in the
WAVES study which reported $100 \%$ occlusion at 30 days using the same NBCA system. However, the latter allowed operators to inject additional glue in larger veins according to their discretion. $^{32}$ Other reported determinants of failure were operator experience, anatomical variation (e.g., aneurysms, junction of large varicosities), ${ }^{29}$ development of incompetency in a once competent vein, intraluminal thrombus formation (most relevant for failure after thermal ablation), and missing the vein altogether. ${ }^{12,22,25,26,29}$

There is no officially reported incidence of DVT for NBCA but it is understood to be very low especially if tip of catheter is positioned $5 \mathrm{~cm}$ away from the superficial-to-deep vein junction. RFA carries a risk of 0 to $16 \%$ and EVLA 0 to $7.7 \%$. Routine postoperative DUS may pick up asymptomatic thrombi. ${ }^{39}$ The benefit of anticoagulation for such DVTs is debatable as most resolve spontaneously. Ultrasound guidelines distinguishing thrombus from glue are also lacking. ${ }^{26}$ No details about length of stockings were provided (example: thigh high or below knee). Bruising was least after NBCA, particularly when glue injection was stopped $2 \mathrm{~cm}$ proximal to the catheter entry site. ${ }^{27}$ A modern laser with longer wavelength $(1,470 \mathrm{~nm})$ causes less ecchymosis than one with shorter wavelength $(810 \mathrm{~nm})$ because it is less damaging to the vessel wall. ${ }^{2,41}$ Prior to this improvement in laser technology RFA was deemed superior to EVLA with regards to postprocedural bruising. ${ }^{19,40,41}$ Other factors implicated in ecchymosis include the use of tumescent anesthesia, phlebectomies, anticoagulants, body mass index, and ethnicity. ${ }^{40}$ Paresthesia typically occurs in 1 to $2 \%$ of cases post-RFA and EVLA, and is rare after NBCA. In the latter it is often mild and selflimiting. ${ }^{2}$ A few recent studies and case reports address the issue of hypersensitivity reactions causing phlebitis-like signs and symptoms in veins treated with cyanoacrylate glue. Generally these respond well to antihistamines and/or steroids, and may even resolve spontaneously. In those veins requiring excision, histological examination identified features of a type IV hypersensitivity reaction to the glue (foreign body). ${ }^{42-44}$ This is different from the phlebitis encountered after thermal ablation. Patients should be asked about cyanoacrylate allergy preoperatively to minimize risks. ${ }^{45}$

This systematic review has some limitations. The comprehensive literature search and data extraction were performed by one author. It excluded mechanochemical ablation and the period of follow-up was short. A meta-analysis would have been ideal but as highlighted in a recent article, the scarcity and heterogeneity of RCTs made this difficult. ${ }^{38}$ As most patients were not sedated, double blinding was impossible. Outcome assessors were often the same ones recruiting, carrying out the treatments and/or following-up patients. This was taken into consideration in part by modifying the Cochrane risk of bias tool. ${ }^{15}$ Some methodologies opted for an induction period to cater for the "learning curve" but others did not. ${ }^{12,34}$ One major inconsistency was in the duration of procedures. There are no set standards as to when time-keeping should start and stop. The lack of reproducibility makes these measurements unreliable.

In terms of patient characteristics, one study included more smokers in the NBCA group and another deviated its 
protocol to include a patient with higher $\mathrm{BMI}^{12,28}$ No differentiation between unilateral or bilateral treatment of varicose veins was made. ${ }^{25,26}$ "Return to normal activities" needs better definition, as these activities are different in an elderly or morbidly obese patient compared with a healthy fit subject. Reflux is best detected in the standing posture on DUS as recommended by the European Society for Vascular Surgery (2015), but some measured this supine. ${ }^{2}$ Lastly, it would be interesting to see a trial addressing NBCA use for varicose veins in anticoagulated patients.

\section{Conclusion}

This systematic review shows the potential benefits of cyanoacrylate glue over RFA and EVLA. Due to its immediate action, occlusion is retained even without postoperative elastic bandages or compression stockings. Patients experienced less pain as there was no tumescent anesthesia, multiple injection sites, or heat involved. Phlebitis is often mild, self-limiting, and attributed to localized skin reaction to the glue. It can be managed conservatively. Procedure times are generally short and patients typically resume work on day 1 or 2 . Failure rates are less but longer-term data are required to affirm this. Cyanoacrylate ablation carries less risk of paresthesia, ecchymosis, and eliminates burn injuries. The two most readily available NBCA kits can be used on various lengths and diameters of veins (including bilateral cases of appropriate length with a single vial of glue). ${ }^{25}$

\section{Ethical Approval}

Not required as data analysis was performed from previously published data.

\section{Funding}

This research work was partially funded by the Endeavor Scholarship Scheme (Malta) with contribution from the European Social Fund (ESF). These are independent bodies and not affiliated with any author, hospital, or company mentioned in this article.

\section{Conflict of Interest}

None declared by the authors.

\section{Acknowledgments}

Ms Claire Gatt, BSc is the statistician who performed statistical analysis on the data.

Ms Bianca-Maria Dimech, BSc Pharm is the second proofreader of the article.

\section{References}

1 Morrison N, Gibson K, McEnroe S, et al. Randomized trial comparing cyanoacrylate embolization and radiofrequency ablation for incompetent great saphenous veins (VeClose). J Vasc Surg 2015;61(04):985-994

2 Wittens C, Davies AH, Bækgaard N, et al; Esvs Guidelines Committee. Editor's choice-management of chronic venous disease: clinical practice guidelines of the European Society for Vascular Surgery (ESVS). Eur J Vasc Endovasc Surg 2015;49 (06):678-737
3 Attaran RR. Latest innovations in the treatment of venous disease. J Clin Med 2018;7(04):77

4 Pavlović MD, Schuller-Petrović S. Endovascular techniques for the treatment of chronic insufficiency of the lower limb's superficial venous system. Rev Vasc Med 2014;2(04):107-117

5 Varicose veins: diagnosis and management (Clinical Guideline 168) [Internet]. National Institute for Health and Care Excellence; 2013 (Updated March 2018). Available at: https://www.nice.org.uk/guidance/cg168. Accessed November 25, 2018

6 Cyanoacrylate glue occlusion for varicose veins (Interventional procedures guidance 526) [Internet]. National Institute for Health and Care Excellence; 2015. Available at: https://www.nice.org.uk/ guidance/ipg526. Accessed November 25, 2018

7 Almeida JI, Javier JJ, Mackay E, Bautista C, Proebstle TM. First human use of cyanoacrylate adhesive for treatment of saphenous vein incompetence. J Vasc Surg Venous Lymphat Disord 2013;1 (02):174-180

8 Dimech A, Cassar K. Efficacy of cyanoacrylate glue ablation of primary truncal varicose veins compared to existing endovenous techniques: a systematic review of the literature. [Internet]. PROSPERO; 2018. Available at: http://www.crd.york.ac.uk/PROSPERO/ display_record.php?ID=CRD42018106323. Accessed September 17, 2018

9 Liberati A, Altman DG, Tetzlaff J, Mulrow C, Gotzsche PC, Ioannidis JPA, et al. The PRISMA statement for reporting systematic reviews and meta-analyses of studies that evaluate healthcare interventions: explanation and elaboration. BMJ 2009;339:b2700

10 Bozkurt AK, Yilmaz MF. A prospective comparison of a new cyanoacrylate glue and laser ablation for the treatment of venous insufficiency. Phlebology 2016;31(Suppl 1):106-113

11 Vasquez MA, Munschauer CE. Venous clinical severity score and quality-of-life assessment tools: application to vein practice. Phlebology 2008;23(06):259-275

12 Morrison N, Gibson K, Vasquez M, et al. VeClose trial 12-month outcomes of cyanoacrylate closure versus radiofrequency ablation for incompetent great saphenous veins. J Vasc Surg Venous Lymphat Disord 2017;5(03):321-330

13 Park I. Initial outcomes of cyanoacrylate closure, VenaSeal system, for the treatment of the incompetent great and small saphenous veins. Vasc Endovascular Surg 2017;51(08):545-549

14 Higgins JPT, Altman DG, Sterne JAC. Assessing risk of bias in included studies. In: Higgins JPT, Green S, eds. Cochrane Handbook for Systematic Reviews of Interventions Version 5.1.0 (updated March 2011). Chichester, United KIngdom: The Cochrane Collaboration; 2011. Available at: www.handbook.cochrane.org. Accessed November 25, 2018

15 Hamann SAS, Giang J, De Maeseneer MGR, Nijsten TEC, van den Bos RR. Editor's choice-five year results of great saphenous vein treatment: a meta-analysis. Eur J Vasc Endovasc Surg 2017;54 (06):760-770

16 Downs SH, Black N. The feasibility of creating a checklist for the assessment of the methodological quality both of randomised and non-randomised studies of health care interventions. J Epidemiol Community Health 1998;52(06):377-384

17 National Heart. Lung and Blood Institute: quality assessment tool for before-after (pre-post) studies with no control group [Internet]. National Heart, Lung and Blood Institute Available at: https://www.nhlbi.nih.gov/health-topics/study-quality-assessment-tools. Accessed Feb 15, 2019

18 Lane TRA, Kelleher D, Moore HM, Franklin IJ, Davies AH. Cyanoacrylate glue for the treatment of great saphenous vein incompetence in the anticoagulated patient. J Vasc Surg Venous Lymphat Disord 2013;1(03):298-300

19 Eroglu E, Yasim A. A randomised clinical trial comparing $N$-butyl cyanoacrylate, radiofrequency ablation and endovenous laser ablation for the treatment of superficial venous incompetence: two year follow up results. Eur J Vasc Endovasc Surg 2018;56(04):553-560 
20 Eroglu E, Yasim A, Ari M, et al. Mid-term results in the treatment of varicose veins with N-butyl cyanoacrylate. Phlebology 2017;32 (10):665-669

21 Yang GK, Parapini M, Gagnon J, Chen JC. Comparison of cyanoacrylate embolization and radiofrequency ablation for the treatment of varicose veins. Phlebology 2019;34(04):278-283

22 Koramaz İ, El Kılıç H, Gökalp F, et al. Ablation of the great saphenous vein with nontumescent $n$-butyl cyanoacrylate versus endovenous laser therapy. J Vasc Surg Venous Lymphat Disord 2017;5(02):210-215

23 Burns PB, Rohrich RJ, Chung KC. The levels of evidence and their role in evidence-based medicine. Plast Reconstr Surg 2011;128 (01):305-310

24 Hooper P, Jutai JW, Strong G, Russell-Minda E. Age-related macular degeneration and low-vision rehabilitation: a systematic review. Can J Ophthalmol 2008;43(02):180-187

25 Chan YC, Law Y, Cheung GC, Ting AC, Cheng SW. Cyanoacrylate glue used to treat great saphenous reflux: measures of outcome. Phlebology 2017;32(02):99-106

26 Chan YC, Law Y, Cheung GC, Cheng SW. Predictors of recanalization for incompetent great saphenous veins treated with cyanoacrylate glue. J Vasc Interv Radiol 2017;28(05):665-671

27 Yavuz T, Acar AN, Aydın H, Ekingen E. A retrospective study of a new n-butyl-2-cyanoacrylate glue ablation catheter incorporated with application guiding light for the treatment of venous insufficiency: twelve-month results. Vascular 2018;26(05):547-555

28 Almeida JI, Javier JJ, Mackay EG, Bautista C, Cher DJ, Proebstle TM. Thirty-sixth-month follow-up of first-in-human use of cyanoacrylate adhesive for treatment of saphenous vein incompetence. J Vasc Surg Venous Lymphat Disord 2017;5(05):658-666

29 Çalık ES, Arslan Ü, Ayaz F, et al. N-butyl cyanoacrylate in the treatment of venous insufficiency-the effect of embolisation with ablative polymerisation. Vasa 2016;45(03):241-246

30 Tekin AI, Tuncer ON, Memetoğlu ME, et al. Nonthermal, nontumescent endovenous treatment of varicose veins. Ann Vasc Surg 2016;36:231-235

31 Bademci MS, Tayfur K, Ocakoglu G, Yazman S, Akyüz M, Yasa H. A new percutaneous technique: $N$-butyl cyanoacrylate adhesive for the treatment of giant saphenous vein insufficiency. Vascular 2018;26(02):194-197

32 Gibson K, Ferris B. Cyanoacrylate closure of incompetent great, small and accessory saphenous veins without the use of postprocedure compression: initial outcomes of a post-market evaluation of the VenaSeal System (the WAVES Study). Vascular 2017; 25(02):149-156

33 Proebstle TM, Alm J, Dimitri S, et al. The European multicenter cohort study on cyanoacrylate embolization of refluxing great saphenous veins. J Vasc Surg Venous Lymphat Disord 2015;3 (01):2-7
34 Kolluri R, Gibson K, Cher D, Madsen M, Weiss R, Morrison N. Rollin phase analysis of clinical study of cyanoacrylate closure for incompetent great saphenous veins. J Vasc Surg Venous Lymphat Disord 2016;4(04):407-415

35 Vasquez MA, Rabe E, McLafferty RB, et al; American Venous Forum Ad Hoc Outcomes Working Group. Revision of the venous clinical severity score: venous outcomes consensus statement: special communication of the American Venous Forum Ad Hoc Outcomes Working Group. J Vasc Surg 2010;52(05): 1387-1396

36 Kailasnath P, Chaloupka JC. Quantitative assessment of polymerization-binding mechanics of cyanoacrylates: model development and validation. AJNR Am J Neuroradiol 2002;23(05):772-778

37 Wang YM, Cheng LF, Li N. Histopathological study of vascular changes after intra-arterial and intravenous injection of $\mathrm{N}$-butyl2-cyanoacrylate. Chin J Dig Dis 2006;7(03):175-179

38 Bissacco D, Stegher S, Calliari FM, Viani MP. Saphenous vein ablation with a new cyanoacrylate glue device: a systematic review on 1000 cases. Minim Invasive Ther Allied Technol 2019;28(01):6-14

39 Choi JH, Park H-C, Joh JH. The occlusion rate and patterns of saphenous vein after radiofrequency ablation. J Korean Surg Soc 2013;84(02):107-113

40 Nordon IM, Hinchliffe RJ, Brar R, et al. A prospective double-blind randomized controlled trial of radiofrequency versus laser treatment of the great saphenous vein in patients with varicose veins. Ann Surg 2011;254(06):876-881

41 Goode SD, Chowdhury A, Crockett M, et al. Laser and radiofrequency ablation study (LARA study): a randomised study comparing radiofrequency ablation and endovenous laser ablation (810 nm). Eur J Vasc Endovasc Surg 2010;40(02): 246-253

42 Jones AD, Boyle EM, Woltjer R, JundtJP, Williams AN. Persistent type IV hypersensitivity after cyanoacrylate closure of the great saphenous vein. J Vasc Surg Cases Innov Tech 2019;5(03):372-374

43 Park I, Jeong MH, Park CJ, Park WI, Park DW, Joh JH. Clinical features and management of "phlebitis-like abnormal reaction" after cyanoacrylate closure for the treatment of incompetent saphenous veins. Ann Vasc Surg 2019;55:239-245

44 Nasser H, Ivanics T, Shakaroun D, Lin J. Severe phlebitis-like abnormal reaction following great saphenous vein cyanoacrylate closure. J Vasc Surg Venous Lymphat Disord 2019;7(04): 578-582

45 Tang TY, Rathnaweera HP, Kam JW, Chong TT, Choke EC, Tan YK. Endovenous cyanoacrylate glue to treat varicose veins and chronic venous insufficiency-Experience gained from our first 100+ truncal venous ablations in a multi-ethnic Asian population using the Medtronic VenaSealTM Closure System. Phlebology: The Journal of Venous Disease. Phlebology 2019;34(08):543-551 